\title{
Algorithmic and analytical approach to the split common fixed points problem
}

\author{
Li-Jun Zhu', Yeong-Cheng Liou ${ }^{2,3}$, Shin Min Kang ${ }^{4 *}$ and Yonghong Yao ${ }^{5}$
}

\author{
"Correspondence: \\ smkang@gnu.ac.kr \\ ${ }^{4}$ Department of Mathematics and \\ RINS, Gyeongsang National \\ University, Jinju, 660-701, Korea \\ Full list of author information is \\ available at the end of the article
}

\begin{abstract}
The split problem, especially the split common fixed point problem, has been studied by many authors. In this paper, we study the split common fixed point problem for the pseudo-contractive mappings and the quasi-nonexpansive mappings. We suggest and analyze an iterative algorithm for solving this split common fixed point problem. A weak convergence theorem is given.
\end{abstract}

MSC: 49J53; 49M37; 65K10; 90C25

Keywords: split common fixed point problem; pseudo-contractive mappings; quasi-nonexpansive mapping; weak convergence

\section{Introduction}

This article we devote to the split common fixed point problem and study it for the pseudocontractive and quasi-nonexpansive mappings. The split common fixed point problem is a generalization of the convex feasibility problem which is to find a point $x^{*}$ satisfying the following:

$$
x^{*} \in \bigcap_{i=1}^{m} C_{i} \text {, }
$$

where $m \geq 1$ is an integer, and each $C_{i}$ is a nonempty closed convex subset of a Hilbert space $H$. Note that the convex feasibility problem has received a lot of attention due to its extensive applications in many applied disciplines as diverse as approximation theory, image recovery and signal processing, control theory, biomedical engineering, communications, and geophysics (see [1-3] and the references therein). A special case of the convex feasibility problem is the split feasibility problem, which is to find a point $x^{*}$ such that

$$
x^{*} \in C \text { and } A x^{*} \in Q \text {, }
$$

where $C$ and $Q$ are two closed convex subsets of two Hilbert spaces $H_{1}$ and $H_{2}$, respectively, and $A: H_{1} \rightarrow H_{2}$ is a bounded linear operator. Such problems arise in the field of intensity-modulated radiation therapy when one attempts to describe physical dose constraints and equivalent uniform dose constraints within a single model; see [4]. The problem with only a single pair of sets $C \in \mathbb{R}^{N}$ and $Q \in \mathbb{R}^{M}$ was first introduced by Censor and Elfving [5]. They used their simultaneous multi-projections algorithm to solve the split 
feasibility problem. Their algorithms, as well as others, see, e.g., Byrne [6], involve matrix inversion at each iterative step. Calculating inverses of matrices is very time-consuming, particularly if the dimensions are large. Therefore, a new algorithm for solving the split feasibility problem was devised by Byrne [7], called the CQ-algorithm:

$$
x_{n+1}=P_{C}\left(x_{n}-\tau A^{*}\left(I-P_{Q}\right) A x_{n}\right) \text {, }
$$

where $\tau \in\left(0, \frac{2}{L}\right)$ with $L$ being the largest eigenvalue of the matrix $A^{*} A, I$ is the unit matrix or operator and $P_{C}$ and $P_{Q}$ denote the orthogonal projections onto $C$ and $Q$, respectively. In the case of nonlinear constraint sets, orthogonal projections may demand a great amount of work of solving a nonlinear optimization problem to minimize the distance between the point and the constraint set. However, it can easily be estimated by linear approximation using the current constraint violation and the sub-gradient at the current point. This was done by Yang, in his recent paper [8], where he proposed a relaxed version of the CQ-algorithm in which orthogonal projections are replaced by sub-gradient projections, which are easily executed when the sets $C$ and $Q$ are given as lower level sets of convex functions; see also [9]. There are a large number of references on the CQ method for the split feasibility problem in the literature; see, for instance, [10-25].

It is our main purpose in this paper to develop algorithms for the split common fixed point for the pseudo-contractive and quasi-nonexpansive mappings. Weak convergence theorem is given. Our results improve and develop previously discussed feasibility problems and related algorithms.

\section{Preliminaries}

Let $H$ be a real Hilbert space with inner product $\langle\cdot, \cdot\rangle$ and norm $\|\cdot\|$, respectively. Let $C$ be a nonempty closed convex subset of $H$.

Definition 2.1 A mapping $S: C \rightarrow C$ is called pseudo-contractive if

$$
\langle S x-S y, x-y\rangle \leq\|x-y\|^{2}
$$

for all $x, y \in C$.

We will use $\operatorname{Fix}(S)$ to denote the set of fixed points of $S$, that is, $\operatorname{Fix}(S)=\{x \in C: x=S x\}$.

Remark 2.2 It is clear that $S$ is pseudo-contractive if and only if

$$
\|S x-S y\|^{2} \leq\|x-y\|^{2}+\|(I-S) x-(I-S) y\|^{2}
$$

for all $x, y \in C$.

Interest in pseudo-contractive mappings stems mainly from their firm connection with the class of nonlinear accretive operators. It is a classical result, see Deimling [26], that if $S$ is an accretive operator, then the solutions of the equations $S x=0$ correspond to the equilibrium points of some evolution systems. 
Definition 2.3 A mapping $T: C \rightarrow C$ is called L-Lipschitzian if there exists $L>0$ such that

$$
\|T x-T y\| \leq L\|x-y\|
$$

for all $x, y \in C$

Remark 2.4 We call $T$ nonexpansive if $L=1$ and $T$ is contractive if $L<1$.

Definition 2.5 A mapping $T: C \rightarrow C$ is called quasi-nonexpansive if

$$
\left\|T x-x^{*}\right\| \leq\left\|x-x^{*}\right\|, \quad \forall\left(x, x^{*}\right) \in C \times \operatorname{Fix}(T) .
$$

Remark 2.6 It is obvious that if $T$ is nonexpansive with $\operatorname{Fix}(T) \neq \emptyset$, then $T$ is quasinonexpansive.

Usually, the convergence of fixed point algorithms requires some additional smoothness properties of the mapping $T$ such as demi-closedness.

Definition 2.7 A mapping $T$ is said to be demi-closed if, for any sequence $\left\{x_{k}\right\}$ which weakly converges to $\tilde{x}$, and if the sequence $\left\{T\left(x_{k}\right)\right\}$ strongly converges to $z$, then $T(\tilde{x})=z$.

It is well known that in a real Hilbert space $H$, the following equality holds:

$$
\|t x+(1-t) y\|^{2}=t\|x\|^{2}+(1-t)\|y\|^{2}-t(1-t)\|x-y\|^{2}
$$

for all $x, y \in H$ and $t \in[0,1]$.

Lemma 2.8 ([27]) Let $H$ be a real Hilbert space, $C$ a closed convex subset of $H$. Let $U$ : $C \rightarrow C$ be a continuous pseudo-contractive mapping. Then

(i) Fix $(U)$ is a closed convex subset of $C$,

(ii) $(I-U)$ is demi-closed at zero.

Lemma 2.9 ([28]) Let $H$ be a Hilbert space and let $\left\{u_{n}\right\}$ be a sequence in $H$ such that there exists a nonempty set $\Omega \subset H$ satisfying the following:

(i) for every $u \in \Omega, \lim _{n}\left\|u_{n}-u\right\|$ exists,

(ii) any weak-cluster point of the sequence $\left\{u_{n}\right\}$ belongs in $\Omega$.

Then there exists $x^{\dagger} \in \Omega$ such that $\left\{u_{n}\right\}$ weakly converges to $x^{\dagger}$.

In the sequel we shall use the following notation:

1. $\omega_{w}\left(u_{n}\right)=\left\{x: \exists u_{n_{j}} \rightarrow x\right.$ weakly $\}$ denote the weak $\omega$-limit set of $\left\{u_{n}\right\}$;

2. $u_{n} \rightarrow x$ stands for the weak convergence of $\left\{u_{n}\right\}$ to $x$;

3. $u_{n} \rightarrow x$ stands for the strong convergence of $\left\{u_{n}\right\}$ to $x$.

\section{Main results}

In this section, we will focus our attention on the following general two-operator split common fixed point problem:

$$
\text { find } x^{*} \in C \text { such that } A x^{*} \in Q \text {, }
$$


where $A: H_{1} \rightarrow H_{2}$ is a bounded linear operator, $U: H_{1} \rightarrow H_{1}$ is a pseudo-contractive mapping and $\mathrm{T}: \mathrm{H}_{2} \rightarrow \mathrm{H}_{2}$ is a quasi-nonexpansive mapping with nonempty fixed point sets $\operatorname{Fix}(U)=C$ and $\operatorname{Fix}(T)=Q$, and we denote the solution set of the two-operator split common fixed point problem by

$$
\Gamma=\{x \in C ; A x \in Q\} .
$$

To solve (3.1), Censor and Segal [12] proposed and proved, in finite-dimensional spaces, the convergence of the following algorithm:

$$
x_{k+1}=U\left(x_{k}+\gamma A^{*}(T-I) A x_{k}\right), \quad k \in \mathbb{N},
$$

where $\gamma \in\left(0, \frac{2}{\lambda}\right)$, with $\lambda$ being the largest eigenvalue of the matrix $A^{*} A$.

Moudafi [16] extended (3.2) to the following relaxed algorithm:

$$
x_{k+1}=U_{\alpha_{k}}\left(x_{k}+\gamma A^{*}\left(T_{\beta}-I\right) A x_{k}\right), \quad k \in \mathbb{N},
$$

where $\beta \in(0,1), \alpha_{k} \in(0,1)$ are relaxation parameters.

Inspired by their works, we introduce the following algorithm.

Algorithm 3.1 Let $H_{1}$ and $H_{2}$ be two real Hilbert spaces. Let $A: H_{1} \rightarrow H_{2}$ be a bounded linear operator. Let $U: H_{1} \rightarrow H_{1}$ be a pseudo-contractive mapping with Lipschitzian constant $L$ and $T: H_{2} \rightarrow H_{2}$ be a quasi-nonexpansive mapping with nonempty $\operatorname{Fix}(U)=C$ and $\operatorname{Fix}(T)=Q$. Let $x_{0} \in H_{1}$. Define a sequence $\left\{u_{n}\right\}$ as follows:

$$
\left\{\begin{array}{l}
x_{n}=u_{n}+\gamma \nu A^{*}(T-I) A u_{n}, \\
y_{n}=\left(1-\xi_{n}\right) x_{n}+\xi_{n} U x_{n}, \\
u_{n+1}=\left[1-\left(1-\delta_{n}\right) \alpha_{n}\right] x_{n}+\left(1-\delta_{n}\right) \alpha_{n} U y_{n}
\end{array}\right.
$$

for all $n \in \mathbb{N}$, where $\gamma$ and $v$ are two constants, $\left\{\alpha_{n}\right\},\left\{\delta_{n}\right\}$, and $\left\{\xi_{n}\right\}$ are three sequences in $[0,1]$.

In the sequel, we assume the parameters satisfy the following restrictions.

\section{Parameters restrictions:}

$\left(\mathrm{R}_{1}\right): 0<\nu<1$ and $0<\gamma<\frac{1}{\lambda \nu}$, where $\lambda$ is the largest eigenvalue of the matrix $A^{*} A$;

$\left(\mathrm{R}_{2}\right): 0<\liminf _{n \rightarrow \infty} \alpha_{n} \leq \limsup _{n \rightarrow \infty} \alpha_{n}<1$;

$\left(\mathrm{R}_{3}\right): 0<k \leq 1-\delta_{n} \leq \xi_{n}<\frac{1}{\sqrt{1+L^{2}}+1}$ for all $n \in \mathbb{N}$, where $L$ is the Lipschitz constant of $U$.

Remark 3.2 Without loss of generality, we may assume that the Lipschitz constant $L>1$. It is obvious that $\frac{1}{\sqrt{1+L^{2}}+1}<\frac{1}{L}$ for all $n \geq 1$. Since $\xi_{n}<\frac{1}{\sqrt{1+L^{2}}+1}$, we have $1-2 \xi_{n}-\xi_{n}^{2} L^{2}>0$ for all $n \in \mathbb{N}$.

Theorem 3.3 Let $H_{1}$ and $H_{2}$ be two real Hilbert spaces. Let $A: H_{1} \rightarrow H_{2}$ be a bounded linear operator. Let $U: H_{1} \rightarrow H_{1}$ be a pseudo-contractive mapping with Lipschitzian constant $L$ and $\mathrm{T}: \mathrm{H}_{2} \rightarrow \mathrm{H}_{2}$ be a quasi-nonexpansive mapping with nonempty $\operatorname{Fix}(U)=C$ and $\operatorname{Fix}(T)=Q$. Assume that $T-I$ is demi-closed at 0 and $\Gamma \neq \emptyset$. Then the sequence $\left\{u_{n}\right\}$ generated by algorithm (3.3) weakly converges to a split common fixed point $\mu \in \Gamma$. 
Proof Let $x^{*} \in \Gamma$. Then we get $x^{*} \in \operatorname{Fix}(U)$ and $A x^{*} \in \operatorname{Fix}(T)$. From (2.2) and (3.3), we have

$$
\begin{aligned}
\left\|u_{n+1}-x^{*}\right\|^{2}= & \left\|\left[1-\left(1-\delta_{n}\right) \alpha_{n}\right] x_{n}+\left(1-\delta_{n}\right) \alpha_{n} U y_{n}-x^{*}\right\|^{2} \\
= & \left\|\left(1-\alpha_{n}\right)\left(x_{n}-x^{*}\right)+\alpha_{n}\left[\delta_{n} x_{n}+\left(1-\delta_{n}\right) U y_{n}-x^{*}\right]\right\|^{2} \\
= & \left(1-\alpha_{n}\right)\left\|x_{n}-x^{*}\right\|^{2}+\alpha_{n}\left\|\delta_{n} x_{n}+\left(1-\delta_{n}\right) U y_{n}-x^{*}\right\|^{2} \\
& -\alpha_{n}\left(1-\alpha_{n}\right)\left\|\delta_{n} x_{n}+\left(1-\delta_{n}\right) U y_{n}-x_{n}\right\|^{2} \\
= & \alpha_{n}\left[\delta_{n}\left\|x_{n}-x^{*}\right\|^{2}+\left(1-\delta_{n}\right)\left\|U y_{n}-x^{*}\right\|^{2}-\delta_{n}\left(1-\delta_{n}\right)\left\|U y_{n}-x_{n}\right\|^{2}\right] \\
& +\left(1-\alpha_{n}\right)\left\|x_{n}-x^{*}\right\|^{2}-\alpha_{n}\left(1-\alpha_{n}\right)\left\|\delta_{n} x_{n}+\left(1-\delta_{n}\right) U y_{n}-x_{n}\right\|^{2} .
\end{aligned}
$$

Since $x^{*} \in \operatorname{Fix}(U)$, we have from $(2.1)$

$$
\left\|U x-x^{*}\right\|^{2} \leq\left\|x-x^{*}\right\|^{2}+\|x-U x\|^{2}
$$

for all $x \in C$.

By (3.4) and (3.5), we obtain

$$
\begin{aligned}
\left\|U y_{n}-x^{*}\right\|^{2}= & \left\|U\left(\left(1-\xi_{n}\right) x_{n}+\xi_{n} U x_{n}\right)-x^{*}\right\|^{2} \\
\leq & \left\|\left(1-\xi_{n}\right) x_{n}+\xi_{n} U x_{n}-U y_{n}\right\|^{2}+\left\|\left(1-\xi_{n}\right) x_{n}+\xi_{n} U x_{n}-x^{*}\right\|^{2} \\
= & \left\|\left(1-\xi_{n}\right)\left(x_{n}-U y_{n}\right)+\xi_{n}\left(U x_{n}-U y_{n}\right)\right\|^{2} \\
& +\left\|\left(1-\xi_{n}\right)\left(x_{n}-x^{*}\right)+\xi_{n}\left(U x_{n}-x^{*}\right)\right\|^{2} \\
= & \left(1-\xi_{n}\right)\left\|x_{n}-U y_{n}\right\|^{2}+\xi_{n}\left\|U x_{n}-U y_{n}\right\|^{2}-\xi_{n}\left(1-\xi_{n}\right)\left\|x_{n}-U x_{n}\right\|^{2} \\
& +\left(1-\xi_{n}\right)\left\|x_{n}-x^{*}\right\|^{2}+\xi_{n}\left\|U x_{n}-x^{*}\right\|^{2}-\xi_{n}\left(1-\xi_{n}\right)\left\|x_{n}-U x_{n}\right\|^{2} \\
\leq & \left(1-\xi_{n}\right)\left\|x_{n}-x^{*}\right\|^{2}+\xi_{n}\left(\left\|x_{n}-x^{*}\right\|^{2}+\left\|x_{n}-U x_{n}\right\|^{2}\right) \\
& -\xi_{n}\left(1-\xi_{n}\right)\left\|x_{n}-U x_{n}\right\|^{2}+\left(1-\xi_{n}\right)\left\|x_{n}-U y_{n}\right\|^{2}+\xi_{n}\left\|U x_{n}-U y_{n}\right\|^{2} \\
& -\xi_{n}\left(1-\xi_{n}\right)\left\|x_{n}-U x_{n}\right\|^{2} .
\end{aligned}
$$

Note that $U$ is $L$-Lipschitzian and $x_{n}-y_{n}=\xi_{n}\left(U x_{n}-x_{n}\right)$. Then we have

$$
\begin{aligned}
\left\|U y_{n}-x^{*}\right\|^{2} \leq & \left(1-\xi_{n}\right)\left\|x_{n}-x^{*}\right\|^{2}+\xi_{n}\left(\left\|x_{n}-x^{*}\right\|^{2}+\left\|x_{n}-U x_{n}\right\|^{2}\right) \\
& -\xi_{n}\left(1-\xi_{n}\right)\left\|x_{n}-U x_{n}\right\|^{2}+\left(1-\xi_{n}\right)\left\|x_{n}-U y_{n}\right\|^{2}+\xi_{n}^{3} L^{2}\left\|x_{n}-U x_{n}\right\|^{2} \\
& -\xi_{n}\left(1-\xi_{n}\right)\left\|x_{n}-U x_{n}\right\|^{2} \\
= & \left\|x_{n}-x^{*}\right\|^{2}+\left(1-\xi_{n}\right)\left\|x_{n}-U y_{n}\right\|^{2} \\
& -\xi_{n}\left(1-2 \xi_{n}-\xi_{n}^{2} L^{2}\right)\left\|x_{n}-U x_{n}\right\|^{2} .
\end{aligned}
$$

Substituting (3.6) into (3.4), we have

$$
\begin{aligned}
\left\|u_{n+1}-x^{*}\right\|^{2} \leq & \left(1-\alpha_{n}\right)\left\|x_{n}-x^{*}\right\|^{2}+\alpha_{n}\left\{\delta_{n}\left\|x_{n}-x^{*}\right\|^{2}+\left(1-\delta_{n}\right)\left[\left\|x_{n}-x^{*}\right\|^{2}\right.\right. \\
& \left.+\left(1-\xi_{n}\right)\left\|x_{n}-U y_{n}\right\|^{2}-\xi_{n}\left(1-2 \xi_{n}-\xi_{n}^{2} L^{2}\right)\left\|x_{n}-U x_{n}\right\|^{2}\right]
\end{aligned}
$$




$$
\begin{aligned}
& \left.-\delta_{n}\left(1-\delta_{n}\right)\left\|U y_{n}-x_{n}\right\|^{2}\right\}-\alpha_{n}\left(1-\alpha_{n}\right)\left\|\delta_{n} x_{n}+\left(1-\delta_{n}\right) U y_{n}-x_{n}\right\|^{2} \\
\leq & \left\|x_{n}-x^{*}\right\|^{2}-\alpha_{n}\left(1-\alpha_{n}\right)\left\|\delta_{n} x_{n}+\left(1-\delta_{n}\right) U y_{n}-x_{n}\right\|^{2} .
\end{aligned}
$$

Since $\lambda$ is the spectral radius of the operator $A A^{*}$, we deduce

$$
\left\langle(T-I) A u_{n}, A A^{*}(T-I) A u_{n}\right\rangle \leq \lambda\left\|(T-I) A u_{n}\right\|^{2} .
$$

This together with (3.1) implies that

$$
\begin{aligned}
\left\|x_{n}-x^{*}\right\|^{2}= & \left\|u_{n}+\gamma \nu A^{*}(T-I) A u_{n}-x^{*}\right\|^{2} \\
= & \left\|u_{n}-x^{*}\right\|^{2}+2 \gamma \nu\left\langle A^{*}(T-I) A u_{n}, u_{n}-x^{*}\right\rangle \\
& +\gamma^{2} \nu^{2}\left\|A^{*}(T-I) A u_{n}\right\|^{2} \\
= & \left\|u_{n}-x^{*}\right\|^{2}+2 \gamma \nu\left\langle A^{*}(T-I) A u_{n}, u_{n}-x^{*}\right\rangle \\
& +\gamma^{2} v^{2}\left\langle(T-I) A u_{n}, A A^{*}(T-I) A u_{n}\right\rangle \\
\leq & \left\|u_{n}-x^{*}\right\|^{2}+2 \gamma \nu\left\langle A^{*}(T-I) A u_{n}, u_{n}-x^{*}\right\rangle \\
& +\gamma^{2} v^{2} \lambda\left\|(T-I) A u_{n}\right\|^{2} .
\end{aligned}
$$

Since $T$ is quasi-nonexpansive and $A x^{*} \in \operatorname{Fix}(T)$, we have

$$
\left\|T A u_{n}-A x^{*}\right\| \leq\left\|A u_{n}-A x^{*}\right\| .
$$

At the same time, we have the following equality in Hilbert spaces:

$$
\|x-y\|^{2}=\|x\|^{2}+\|y\|^{2}-2\langle x, y\rangle \text {. }
$$

In (3.9), picking up $x=(T-I) A u_{n}$ and $y=T A u_{n}-A x^{*}$ to deduce

$$
\begin{aligned}
\left\|A u_{n}-A x^{*}\right\|^{2}= & \left\|(T-I) A u_{n}-\left(T A u_{n}-A x^{*}\right)\right\|^{2} \\
= & \left\|(T-I) A u_{n}\right\|^{2}+\left\|T A u_{n}-A x^{*}\right\|^{2} \\
& -2\left\langle(T-I) A u_{n}, T A u_{n}-A x^{*}\right\rangle \\
\leq & \left\|(T-I) A u_{n}\right\|^{2}+\left\|A u_{n}-A x^{*}\right\|^{2} \\
& -2\left\langle(T-I) A u_{n}, T A u_{n}-A x^{*}\right\rangle .
\end{aligned}
$$

It follows that

$$
\left\langle(T-I) A u_{n}, T A u_{n}-A x^{*}\right\rangle \leq \frac{1}{2}\left\|(T-I) A u_{n}\right\|^{2} .
$$

Thus,

$$
\begin{aligned}
\left\langle A^{*}(T-I) A u_{n}, u_{n}-x^{*}\right\rangle & =\left\langle(T-I) A u_{n}, A u_{n}-A x^{*}\right\rangle \\
& =\left\langle(T-I) A u_{n}, T A u_{n}-A x^{*}\right\rangle+\left\langle(T-I) A u_{n}, A u_{n}-T A u_{n}\right\rangle
\end{aligned}
$$




$$
\begin{aligned}
& \leq \frac{1}{2}\left\|(T-I) A u_{n}\right\|^{2}-\left\|(T-I) A u_{n}\right\|^{2} \\
& =-\frac{1}{2}\left\|(T-I) A u_{n}\right\|^{2} .
\end{aligned}
$$

From (3.7), (3.8), and (3.10), we get

$$
\begin{aligned}
\left\|u_{n+1}-x^{*}\right\|^{2} \leq & \left\|u_{n}-x^{*}\right\|^{2}-\gamma v(1-\lambda \gamma \nu)\left\|(T-I) A u_{n}\right\|^{2} \\
& -\alpha_{n}\left(1-\alpha_{n}\right)\left\|\delta_{n} x_{n}+\left(1-\delta_{n}\right) U y_{n}-x_{n}\right\|^{2}
\end{aligned}
$$

We deduce immediately that

$$
\left\|u_{n+1}-x^{*}\right\| \leq\left\|u_{n}-x^{*}\right\|
$$

Hence, $\lim _{n \rightarrow \infty}\left\|u_{n}-x^{*}\right\|$ exists. This implies that $\left\{u_{n}\right\}$ is bounded. Consequently, we have

$$
0 \leq \gamma \nu(1-\lambda \gamma \nu)\left\|(T-I) A u_{n}\right\|^{2} \leq\left\|u_{n}-x^{*}\right\|^{2}-\left\|u_{n+1}-x^{*}\right\|^{2} \rightarrow 0
$$

Therefore,

$$
\lim _{n \rightarrow \infty}\left\|(T-I) A u_{n}\right\|=0
$$

Since $\left\{u_{n}\right\}$ is bounded, $\omega_{w}\left(u_{n}\right) \neq \emptyset$. We can take $\mu \in \omega_{w}\left(u_{n}\right)$, that is, there exists $\left\{u_{n_{j}}\right\}$ such that $\omega-\lim _{j \rightarrow \infty} u_{n_{j}}=\mu$. Noting that $T-I$ is demi-closed at 0 , from (3.12), we obtain

$$
(T-I) A \mu=0 .
$$

Thus, $A \mu \in \operatorname{Fix}(T)$.

From (3.11), we deduce

$$
\alpha_{n}\left(1-\alpha_{n}\right)\left\|\delta_{n} x_{n}+\left(1-\delta_{n}\right) U y_{n}-x_{n}\right\|^{2} \leq\left\|u_{n}-x^{*}\right\|^{2}-\left\|u_{n+1}-x^{*}\right\|^{2} \rightarrow 0
$$

Since $0<\liminf _{n \rightarrow \infty} \alpha_{n} \leq \limsup _{n \rightarrow \infty} \alpha_{n}<1,0<\liminf _{n \rightarrow \infty} \alpha_{n} \leq \limsup _{n \rightarrow \infty} \alpha_{n}(1-$ $\left.\alpha_{n}\right)<1$. Then we have

$$
\lim _{n \rightarrow \infty}\left\|\delta_{n} x_{n}+\left(1-\delta_{n}\right) U y_{n}-x_{n}\right\|=\lim _{n \rightarrow \infty}\left(1-\delta_{n}\right)\left\|U y_{n}-x_{n}\right\|=0
$$

Note that $\lim \sup \delta_{n}<1$; we get immediately

$$
\lim _{n \rightarrow \infty}\left\|U y_{n}-x_{n}\right\|=0
$$

Since $U$ is $L$-Lipschitzian, we have

$$
\begin{aligned}
\left\|U x_{n}-x_{n}\right\| & \leq\left\|U x_{n}-U y_{n}\right\|+\left\|U y_{n}-x_{n}\right\| \\
& \leq L\left\|x_{n}-y_{n}\right\|+\left\|U y_{n}-x_{n}\right\| \\
& =L \xi_{n}\left\|U x_{n}-x_{n}\right\|+\left\|U y_{n}-x_{n}\right\| .
\end{aligned}
$$


It follows that

$$
\left\|U x_{n}-x_{n}\right\| \leq \frac{1}{1-L \xi_{n}}\left\|U y_{n}-x_{n}\right\| \leq \frac{\sqrt{1+L^{2}}+1-L}{\sqrt{1+L^{2}}+1}\left\|U y_{n}-x_{n}\right\| .
$$

So

$$
\lim _{n \rightarrow \infty}\left\|U x_{n}-x_{n}\right\|=0 .
$$

From (3.3), (3.12), and (3.13), we have $\lim _{n \rightarrow \infty}\left\|x_{n}-u_{n}\right\|=0$. Thus, $\omega-\lim _{j \rightarrow \infty} x_{n_{j}}=\mu$. By the demi-closedness of $U-I$ at 0 (Lemma 2.8), we get

$$
U \mu=\mu \text {. }
$$

Hence, $\mu \in \operatorname{Fix}(U)$. Therefore, $\mu \in \Gamma$. Since there is no more than one weak-cluster point, the weak convergence of the whole sequence $\left\{u_{n}\right\}$ follows by applying Lemma 2.9 with $\Omega=\Gamma$. This completes the proof.

Example 3.4 Let $H=\mathbb{R}$ with the inner product defined by $\langle x, y\rangle=x y$ for all $x, y \in \mathbb{R}$ and the standard norm $|\cdot|$. Let $C=[0,+\infty)$ and $T x=\frac{x^{2}+2}{1+x}$ for all $x \in C$. Obviously, $\operatorname{Fix}(T)=2$. It is easy to see that

$$
|T x-2|=\left|\frac{x^{2}+2}{1+x}-2\right|=\frac{x}{1+x}|x-2| \leq|x-2|
$$

for all $x \in C$ and

$$
\left|T(0)-T\left(\frac{1}{3}\right)\right|=\frac{5}{12}>\left|0-\frac{1}{3}\right| .
$$

Hence, $T$ is a continuous quasi-nonexpansive mapping but not nonexpansive.

Example 3.5 Let $H=\mathbb{R}$ with the inner product defined by $\langle x, y\rangle=x y$ for all $x, y \in \mathbb{R}$ and the standard norm $|\cdot|$. Let $C=[0,+\infty)$ and let $U x=x-1+\frac{4}{x+1}$ for all $x \in C$. Observe that $\operatorname{Fix}(U)=3$. It is easy to see that

$$
\begin{aligned}
\langle U x-U y, x-y\rangle & =\left\langle x-1+\frac{4}{x+1}-y+1-\frac{4}{y+1}, x-y\right\rangle \\
& \leq\left[1-\frac{4}{(x+1)(y+1)}\right]|x-y|^{2} \\
& \leq|x-y|^{2}
\end{aligned}
$$

and

$$
\begin{aligned}
|U x-U y| & \leq\left|x-1+\frac{4}{x+1}-y+1-\frac{4}{y+1}\right| \\
& \leq\left|1-\frac{4}{(x+1)(y+1)}\right||x-y| \\
& \leq 5|x-y|
\end{aligned}
$$

for all $x, y \in C$. 
But

$$
\left|U\left(\frac{1}{4}\right)-U(0)\right|=\frac{11}{20}>\frac{1}{4} .
$$

Hence, $U$ is a Lipschitzian pseudo-contractive mapping but it is not nonexpansive.

\section{Competing interests}

The authors declare that they have no competing interests.

\section{Authors' contributions}

All authors read and approved the final manuscript.

\section{Author details}

${ }^{1}$ School of Mathematics and Information Science, Beifang University of Nationalities, Yinchuan, 750021, China.

${ }^{2}$ Department of Information Management, Cheng Shiu University, Kaohsiung, 833, Taiwan. ${ }^{3}$ Center for General Education, Kaohsiung Medical University, Kaohsiung, 807, Taiwan. ${ }^{4}$ Department of Mathematics and RINS, Gyeongsang National University, Jinju, 660-701, Korea. ${ }^{5}$ Department of Mathematics, Tianjin Polytechnic University, Tianjin, 300387, China.

\section{Acknowledgements}

The authors are grateful to the five reviewers for their valuable comments and suggestions. Li-Jun Zhu was supported in part by NNSF of China (61362033) and NZ13087. Yeong-Cheng Liou was supported in part by NSC

101-2628-E-230-001-MY3 and NSC 101-2622-E-230-005-CC3.

Received: 14 March 2014 Accepted: 25 July 2014 Published: 18 Aug 2014

\section{References}

1. Bauschke, $\mathrm{HH}$, Borwein, JM: On projection algorithms for solving convex feasibility problems. SIAM Rev. 38, 367-426 (1996). doi:10.1137/S0036144593251710

2. Combettes, PL: The convex feasibility problem in image recovery. In: Hawkes, P (ed.) Advances in Imaging and Electron Physics, vol. 95, pp. 155-270. Academic Press, New York (1996)

3. Stark, H (ed.): Image Recovery Theory and Applications. Academic Press, Orlando (1987)

4. Censor, Y, Bortfeld, T, Martin, B, Trofimov, A: A unified approach for inversion problems in intensity modulated radiation therapy. Phys. Med. Biol. 51, 2353-2365 (2006). doi:10.1088/0031-9155/51/10/001

5. Censor, Y, Elfving, T: A multiprojection algorithm using Bregman projections in a product space. Numer. Algorithms 8 , 221-239 (1994)

6. Byrne, C: Bregman-Legendre multidistance projection algorithms for convex feasibility and optimization. In: Butnariu, D, Censor, Y, Reich, S (eds.) Inherently Parallel Algorithms in Feasibility and Optimization and Their Applications, pp. 87-100. Elsevier, Amsterdam (2001)

7. Byrne, C: Iterative oblique projection onto convex subsets and the split feasibility problem. Inverse Probl. 18, 441-453 (2002). doi:10.1088/0266-5611/18/2/310

8. Yang, Q: The relaxed CQ algorithm solving the split feasibility problem. Inverse Probl. 20, 1261-1266 (2004). doi:10.1088/0266-5611/20/4/014

9. Zhao, J, Yang, Q: Several solution methods for the split feasibility problem. Inverse Probl. 21, 1791-1799 (2005). doi:10.1088/0266-5611/21/5/017

10. Ceng, LC, Ansari, QH, Yao, JC: An extragradient method for split feasibility and fixed point problems. Comput. Math. Appl. 64, 633-642 (2012). doi:10.1016/j.camwa.2011.12.074

11. Censor, Y, Motova, A, Segal, A: Perturbed projections and subgradient projections for the multiple-sets split feasibility problem. J. Math. Anal. Appl. 327, 1244-1256 (2007). doi:10.1016/j.jmaa.2006.05.010

12. Censor, Y, Segal, A: The split common fixed point problem for directed operators. J. Convex Anal. 16, 587-600 (2009)

13. Dang, Y, Gao, Y: The strong convergence of a KM-CQ-like algorithm for a split feasibility problem. Inverse Probl. 27, 015007 (2011). doi:10.1088/0266-5611/27/1/015007

14. Deepho, J, Kumam, P: A modified Halpern's iterative scheme for solving split feasibility problems. Abstr. Appl. Anal. 2012, Article ID 876069 (2012). doi:10.1155/2012/876069

15. López, G, Martín-Márquez, V, Xu, HK: Iterative algorithms for the multiple-sets split feasibility problem. In: Censor, Y, Jiang, M, Wang, G (eds.) Biomedical Mathematics: Promising Directions in Imaging, Therapy Planning and Inverse Problems, pp. 243-279. Medical Physics Publishing, Madison (2009)

16. Moudafi, A: A note on the split common fixed-point problem for quasi-nonexpansive operators. Nonlinear Anal. 74, 4083-4087 (2011). doi:10.1016/j.na.2011.03.041

17. Wang, F, XU, HK: Approximating curve and strong convergence of the CQ algorithm for the split feasibility problem. J. Inequal. Appl. 2010, Article ID 102085 (2010). doi:10.1155/2010/102085

18. Wang, F, Xu, HK: Cyclic algorithms for split feasibility problems in Hilbert spaces. Nonlinear Anal. 74, $4105-4111$ (2011). doi:10.1016/j.na.2011.03.044

19. Xu, HK: A variable Krasnosel'skii-Mann algorithm and the multiple-set split feasibility problem. Inverse Probl. 22 2021-2034 (2006). doi:10.1088/0266-5611/22/6/007

20. Xu, HK: Iterative methods for the split feasibility problem in infinite-dimensional Hilbert spaces. Inverse Probl. 26 105018 (2010). doi:10.1088/0266-5611/26/10/105018 
21. Yao, Y, Kim, TH, Chebbi, S, Xu, HK: A modified extragradient method for the split feasibility and fixed point problems. J. Nonlinear Convex Anal. 13, 383-396 (2012)

22. Yao, Y, Wu, J, Liou, YC: Regularized methods for the split feasibility problem. Abstr. Appl. Anal. 2012, Article ID 140679 (2012). doi:10.1155/2012/140679

23. Yu, X, Shahzad, N, Yao, Y: Implicit and explicit algorithms for solving the split feasibility problem. Optim. Lett. 6, 1447-1462 (2012). doi:10.1007/s11590-011-0340-0

24. Zhao, J, Yang, Q: Self-adaptive projection methods for the multiple-sets split feasibility problem. Inverse Probl. 27, 035009 (2011). doi:10.1088/0266-5611/27/3/035009

25. Zhang, W, Han, D, Li, Z: A self-adaptive projection method for solving the multiple-sets split feasibility problem. Inverse Probl. 25, 115001 (2009). doi:10.1088/0266-5611/25/11/115001

26. Deimling, K: Zeros of accretive operators. Manuscr. Math. 13, 365-374 (1974)

27. Zhou, $\mathrm{H}$ : Strong convergence of an explicit iterative algorithm for continuous pseudo-contractions in Banach spaces Nonlinear Anal. 70, 4039-4046 (2009). doi:10.1016/..na.2008.08.012

28. Bauschke, HH, Combettes, PL: A weak-to-strong convergence principle for Fejér-monotone methods in Hilbert spaces. Math. Oper. Res. 26, 248-264 (2001). doi:10.1287/moor.26.2.248.10558

10.1186/1687-1812-2014-172

Cite this article as: Zhu et al:: Algorithmic and analytical approach to the split common fixed points problem. Fixed Point Theory and Applications 2014, 2014:172

\section{Submit your manuscript to a SpringerOpen ${ }^{\circ}$ journal and benefit from:}

- Convenient online submission

- Rigorous peer review

- Immediate publication on acceptance

- Open access: articles freely available online

- High visibility within the field

- Retaining the copyright to your article 